\title{
Is there any relationship between dietary patterns and depression and anxiety in Chinese adolescents?
}

\author{
Ting-Ting Weng ${ }^{1,2}$, Jia-Hu Hao ${ }^{1,2, *}$, Qing-Wen Qian ${ }^{3}$, Hui Cao ${ }^{1,2}$, Ji-Ling Fu ${ }^{1,2}$, \\ Ying Sun ${ }^{1,2}$, Lei Huang ${ }^{1,2}$ and Fang-Biao Tao ${ }^{1,2}$ \\ 'Department of Maternal, Child \& Adolescent Health, School of Public Health, Anhui Medical University, 81 \\ Meishan Road, Hefei Province, Anhui 230032, People's Republic of China: ${ }^{2}$ Anhui Provincial Key Laboratory of \\ Population Health \& Aristogenics, Department of Maternal, Child \& Adolescent Health, School of Public Health, \\ Anhui Medical University, Hefei, Anhui, People's Republic of China: ${ }^{3}$ Bengbu Center for Disease Control and \\ Prevention, Bengbu, Anhui, People's Republic of China
}

Submitted 25 March 2011: Accepted 25 October 2011: First published online 25 November 2011

\begin{abstract}
Objective: To determine the association between major dietary patterns characterized by factor analysis and risk of depression and anxiety symptoms among adolescents.

Design: Diet and symptoms of depression and anxiety were assessed in a crosssectional survey among students attending junior high school. Dietary patterns were derived from a self-reported FFQ, which consisted of thirty-eight items. Anthropometric measurements were also performed.

Setting: Four junior high schools in Bengbu city, China.

Subjects: A random sample of 5003 adolescents, 11-16 years of age (mean 13.21 years).

Results: Three major dietary patterns were identified in the study based on factor analysis: 'snack', 'animal food' and 'traditional'. The prevalence of depression symptoms, anxiety disorders and the coexistence of both were $11 \cdot 2 \%$ (560/5003), $14 \cdot 6 \%(732 / 5003)$ and $12 \cdot 6 \%(629 / 5003)$, respectively. After adjustment for potential confounders, adolescents in the highest tertile of snack dietary pattern scores had a higher odds for 'pure' psychological symptoms ('depression without anxiety', OR $=1 \cdot 64 ; 95 \%$ CI $1.30,2 \cdot 06$; and 'anxiety without depression', $\mathrm{OR}=1 \cdot 87 ; 95 \%$ CI $1 \cdot 51,2 \cdot 31)$ compared with coexisting depression and anxiety $(\mathrm{OR}=1 \cdot 93 ; 95 \%$ CI $1 \cdot 54,2 \cdot 43)$. Similar to snacks, high consumption of animal foods was associated with a higher risk of psychological symptoms. Compared with low consumption, adolescents in the highest tertile of traditional dietary pattern scores had lower odds for 'pure' depression (OR $=0 \cdot 38 ; 95 \%$ CI $0 \cdot 30$, $0 \cdot 49)$, 'pure' anxiety $(\mathrm{OR}=0 \cdot 85 ; 95 \% \mathrm{CI} 0 \cdot 69,1 \cdot 04)$ and coexisting anxiety and depression $(\mathrm{OR}=0.50 ; 95 \% \mathrm{CI} 0 \cdot 39,0.63)$.

Conclusions: Data from Chinese secondary-school adolescents validated findings from adult populations. Dietary patterns should be considered as important predictors of depression and anxiety among adolescents in further studies.
\end{abstract}

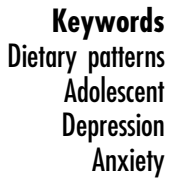

Keywords Adolescent Depression Anxiety
Adolescence is a critical period for mental disorders, with a high percentage of all lifetime mental disorders detected for the first time by age 14 years ${ }^{(1)}$. Globally, approximately $20 \%$ of children and adolescents have mental disorders or mental health-related problems, and half of these cases are diagnosed before the age of 14 years ${ }^{(2)}$. During this period, mental health is strongly related to other developmental and health conditions. Investigations of clinic and community samples report that depression in adolescence can predict further problems by influencing quality of life, academic performance, social activities and even obesity in later life ${ }^{(3-6)}$. It has been reported that there is a high co-occurrence of depression and general anxiety disorders in adolescents $^{(7)}$. Brady and Kendall ${ }^{(8)}$ performed a literature review regarding anxiety and depression in children and adolescents and estimated that 15.9-61.9\% of children with anxiety or depression had co-morbid anxiety and depressive disorders. Because the prevalence of mental disorders is high and causes effects on the physiological and psychological development of adolescents, the prevalence of mental disorders has become a major health problem $^{(2)}$. Therefore, it is necessary to understand potential risk factors for mental health disorders in young 
people in an effort to formulate appropriate measures for early prevention and intervention.

Diet is usually investigated in lifestyle-mediated diseases $^{(9)}$. In recent years, dietary patterns have been the subject of increased attention in the field of adolescent mental health. Researchers noticed that inadequate nutrition and poor diet quality (fast food, confectionery items, animal foods) are more frequently associated with mental problems ${ }^{(10-15)}$. A cross-sectional relationship between diet quality and depression was verified in a large sample of adolescents from a diverse range of sociodemographic backgrounds ${ }^{(13)}$. The intakes of fruit, vegetables, meat, snacks and other healthy foods were also assessed and shown to be related with mental or physical disorders in adolescents ${ }^{(10,16,17)}$. Unlike other diet research methods, dietary pattern analysis is used for characterizing the whole diet in combination. The use of FFQ has been validated in adolescents, sometimes even better than the $24 \mathrm{~h}$ recall approach ${ }^{(18)}$. FFQ can capture complex behaviours and potentially interactive effects among special nutrients that might impact mental health ${ }^{(19)}$. However, there are only a limited number of studies evaluating the association between special dietary patterns and mental disorders in adolescents ${ }^{(10,20)}$. For example, in a recent study conducted in adolescents aged 13-15 years, Oddy et al. ${ }^{(20)}$ suggested that an increased adherence to a Western dietary pattern was associated with higher scores on the Child Behavior Checklist $(\mathrm{CBCL})$, resulting in poorer mental health.

Adolescence is a stage when independence is established. Certain dietary patterns may be adapted by adolescents and might be followed for a long period. Consequently, unhealthy dietary patterns during youth would have profound implications for well-being in adulthood. In China the lifestyle and dietary habits of adolescents have changed in recent decades. Specifically, a higher percentage of urban adolescents consume more fast foods and sweetened beverages ${ }^{(21)}$. There are few studies that have assessed the role of dietary patterns with respect to adolescent mental health in China. Therefore, we determined the associations between major dietary patterns and the prevalence of depression and anxiety among Chinese adolescents.

\section{Methods}

\section{Sample and procedures}

The aerobic exercise intervention study is a school-based study investigating the effect of aerobic exercise on adolescent mental health which was conducted from September 2010 to October 2010 in Bengbu, Anhui Province, China.

The sampling scheme was a one-stage random cluster sample. The cluster sampling frame comprised all twenty-one junior schools in Bengbu city. We randomized four of twenty-one junior high schools (grades 7-9) on the basis of a computer-generated random number table that was in the hands of a person not involved in the study. All students and their parents in the four schools gave informed consent. A self-administered questionnaire survey was administered a week before anthropometric measurements were made. According to anonymous and voluntary participation, students completed questionnaires during one class period ( $45 \mathrm{~min}$ ) without interruptions. The students' height, weight and waist circumference were measured and recorded by trained postgraduate students and school physicians. As of November 2010, 5340 students had completed the baseline questionnaire. There were 265 students who had incomplete anthropometric data and fifty-eight incomplete questionnaires (more than 15\% of information was missing). Fourteen students were excluded for receiving psychotropic medications or mental health treatment during the study period or had a history of substance abuse. A total of 5003 students were available at baseline for follow-up. For the present study we analysed data collected at baseline only.

\section{Instruments}

\section{Dietary assessment}

Habitual dietary patterns were assessed by a comprehensive and self-administered FFQ, which was designed to measure the dietary habits of the adolescents. The time of consumption for each food or food group per week was determined. According to the dietary features of the target population, the FFQ was modified on the basis of a previous questionnaire $^{(22)}$. The FFQ included thirty-eight food items which are commonly consumed by Chinese adolescents. Each item represents a food group. Students were asked to indicate the consumption frequency during the previous $7 \mathrm{~d}$ that best described their intake. There were five frequency options, ranging from 'never' to '9 or more times' per $7 \mathrm{~d}$, excluding alcoholic beverages. Each option was scored as follows: 'never eat' $=0$; ' $1-3$ times' $=1$; ' $4-5$ times' $=2$; ' $6-8$ times' $=3$; and 'more than 8 times' $=4$. The FFQ focused only on the frequency of each food item, and information on the portion size was not included.

\section{Depression and anxiety assessment}

Depression symptoms were measured by the Chinese version of the Depression Self-rating Scale for Children (DSRS), as developed by Birleson ${ }^{(23)}$. The DSRS was adapted to children 8-16 years of age and contained eighteen items, of which students self-reported the frequency of each item during the last week ${ }^{(23,24)}$. Each item response was rated on a 3-point scale from 'never' to 'more frequent'. A cut-off score of 15 was used to screen depression symptoms among children and adolescents. The scale has been validated, having content reliability in local children and young adolescents. The test-retest reliability, the split-half and Cronbach's $\alpha$ were in the 
range $0 \cdot 53-0 \cdot 73$. The total score of the scale also showed a significant correlation with the corresponding subscale of the CBCL $(r=0 \cdot 49-0 \cdot 58)$ and the subscale of the Paiers-Harris Children's Self-concept Scale $(r=0 \cdot 60-0 \cdot 68$; $P$ values both $<0 \cdot 05)^{(24)}$.

The instrument used to screen anxiety symptoms of the students was the Chinese version of the Screen Scale for Child Anxiety Related Emotional Disorders (SCARED), as designed by Birmaher et al. ${ }^{(25)}$, which contained fortyone items allocated to five dimensions: somatic/panic; generalized anxiety; separation anxiety; social phobia; and school phobia. Students were asked to answer the frequency with which they experienced each symptom using a 3-point scale ( $0=$ 'almost never', $1=$ 'sometimes' and $2=$ 'often'). If the total score is more than 23 , an anxiety disorder is screened. The validity and reliability of the SCARED (Chinese version) have been validated in a previous study ${ }^{(26)}$. The Chinese version of the scale also demonstrated good internal consistency, test-retest reliability (intra-class correlation coefficient $=0 \cdot 46-0 \cdot 77$ over 2 weeks and 0.24-0.67 over 12 weeks) and good validity between anxiety and non-anxiety disorders ${ }^{(27)}$.

\section{Antbropometric measurements}

Measurements were performed by a team of trained nurses and interviewers who used the same standard methods in the baseline study. Body height, weight and waist circumference were measured. Positioning of the body was standardized by asking the student to stand straight without shoes and with the heels placed together. Weight was measured to the nearest $0 \cdot 1 \mathrm{~kg}$ using an electronic body weight meter. Students were asked to wear light clothing and empty their bladder. Height was measured to the nearest $0 \cdot 1 \mathrm{~cm}$ with a manual height board. Waist circumference was measured $1 \mathrm{~cm}$ above the umbilicus with a standard tape measure to the nearest $0 \cdot 1 \mathrm{~cm}$. The height and waist circumference were measured twice, and the mean value was recorded. BMI $\left(\mathrm{kg} / \mathrm{m}^{2}\right)$ and waist-to-height ratio (WHtR) were calculated to assess whether students were obese/overweight.

\section{Covariate assessment}

The sociodemographic information included age, gender, grade, family income, number of siblings, and maternal and paternal education. The family income was selfreported and classified in three levels ranging from 'low' ( score $=1$ ) to 'high' (score $=3$ ). Maternal or paternal education was classified in four levels as follows: primary schooling or illiterate $($ score $=1)$; secondary schooling (score $=2)$; university or other tertiary qualification $($ score $=3)$; unknown $($ scored $=4)$. Physical activity was assessed based on the following question: 'How many days in the past week have you had at least one moderate physical activity (i.e. an activity that leaves you out of breath or feeling tired some of the time) for $60 \mathrm{~min}$ or more (never/ $1 \mathrm{~d} / 2 \mathrm{~d} / 3 \mathrm{~d}$ or more)? ${ }^{(28)}$.

\section{Statistical analysis}

We used factor analysis (principal components) to derive dietary patterns based on the FFQ. Thirty-eight food items were entered into the factor analysis, and rotated by orthogonal transformation (varimax rotation) to maintain uncorrelated factors and greater interpretability. Inter-item reliability for each factor was assessed by Cronbach's $\alpha$ coefficients (Cronbach's $\alpha$ for the FFQ was 0.895 in the present study). Items were excluded for the absolute value of factor loading $<0 \cdot 2$ (Table 2 ). We determined to retain three factors according to the eigenvalues in the scree plot, which accounted for $34.78 \%$ of the variance in the dietary information. The three factors were labelled as 'traditional', 'snack' and 'animal food', and scores were saved as variables in the data set. For further statistical analyses, factors were treated categorically (tertiles). Trend associations between categorically demographic variables and dietary patterns were assessed using $\chi^{2}$ analysis. Means (and standard errors) of BMI, WHtR and age were calculated according to tertile of dietary pattern scores using ANOVA, and BMI and WHtR were adjusted for age and gender.

Bivariate logistic regression analysis was performed to estimate the odds of sociodemographic variables for mental disorders. Multinomial logistic regression models, with all three dietary patterns entered simultaneously as exposure variables, and categorical 'pure' depression (depression without anxiety), 'pure' anxiety (anxiety without depression) and coexisting depression and anxiety as dependent variables, were fitted to determine the confounder-controlled association of the three dietary patterns with self-reported mental problems. In each dietary pattern the lowest tertile was designated as the reference group. Statistical analyses were performed with the SPSS statistical software package version $10 \cdot 0$ (SPSS, Inc., Chicago, IL, USA). Differences were considered significant if $P<0 \cdot 05$.

\section{Results}

We assessed 2606 boys and 2397 girls in the present study. The mean age at recruitment was $13 \cdot 21$ (SD 0.99) years. Three dietary patterns were extracted from thirtyeight food groups (Table 1) in the FFQ using principal component analysis: snack, animal food and traditional. The factor-loading matrices for the three patterns are listed in Table 2 . The snack dietary pattern was composed mainly of preserved fruit, a sweet course, frozen confection, yoghurt, chocolate, candy and carbonated drinks. The animal dietary pattern consisted of red meat, organ meat, processed meat, fried meat and other Chinese meat dishes. The traditional dietary pattern is a typically healthy and recommended diet, and included foods such as gruel, oatmeal, whole grains, fresh yellow or red vegetables, fruit and soya milk. 
Table 1 The thirty-eight food items in the FFQ with examples

\begin{tabular}{|c|c|c|}
\hline & Food item & Examples \\
\hline 1. & Staple food (for most Chinese) & Rice, noodles \\
\hline 2. & Bread & White bread, whole-wheat bread, toast \\
\hline 3. & Pancake & Chinese oil cake, batter cake \\
\hline 4. & Chinese traditional congee & Corn congee, millet congee \\
\hline 5. & Porridge & Porridge \\
\hline 6. & Whole grains & Corn, sweet potato (boiled or baked) \\
\hline 7. & Red meat & Beef, lamb, pork (not fried) \\
\hline 8. & Organ meat & Pig and other animals' bowels, blood (not fried) \\
\hline 9. & Poultry & Chicken, duck, goose (not fried) \\
\hline 10. & Fish and other fishery products & Fish, shrimp (not fried) \\
\hline 11. & Processed meat & Sausage, ham \\
\hline 12. & Preserved meat & Preserved pork, preserved beef \\
\hline 13. & Chinese traditional meat dishes & Meat balls \\
\hline 14. & Egg & Egg (including yolk) \\
\hline 15. & Western fast food & Hamburger, pizza \\
\hline 16. & Chinese fast food & Steamed stuffed-bun, Chinese hamburger \\
\hline 17. & Fried meat & Chicken, beef, pork (fried) \\
\hline 18. & Fried vegetables & Potato, sea tangle, soya products (fried) \\
\hline 19. & Roast meat & Shish kebab (Chinese traditional dish) \\
\hline 20. & Fried pasta & Twisted cruller (Chinese style), spring roll \\
\hline 21. & Fresh yellow or red vegetables & Carrot, tomato, big capsicums (all not fried) \\
\hline 22. & Fresh green leafy vegetables & Spinach, Chinese cabbage, leaf lettuce \\
\hline 23. & Fresh fruit & Apple, orange, banana \\
\hline 24. & Preserved fruit & Prune, raisin \\
\hline 25. & Soya products & Tofu, dried tofu \\
\hline 26. & Soya milk & Soya milk \\
\hline 27. & Milk & Raw milk, powdered milk (including whole, low-fat or fat-free milk) \\
\hline 28. & Yoghurt & Yoghurt (including frozen yoghurt) \\
\hline 29. & Sweet course & Cake, biscuit, cookie \\
\hline 30. & Ice cream & Ice cream, ice cream bars (including low-fat or fat-free) \\
\hline 31. & Chocolate & Chocolate, chocolate wafer \\
\hline 32. & Candy & Candy \\
\hline 33. & Nuts & Peanut, walnut, melon seed, cashew \\
\hline 34. & Tea & Tea, tea drink \\
\hline 35. & Carbonated beverages & Cola, sprite \\
\hline 36. & Flavoured milk drink & Flavoured milk drink \\
\hline 37. & Fruit/vegetable juice & Tomato juice, orange juice \\
\hline 38. & Sauerkraut & Pickle, salted egg \\
\hline
\end{tabular}

The distribution of students' sociodemographic and anthropometric characteristics across the three dietary patterns is shown in Table 3. A higher consumption of the snack dietary pattern was associated with female gender, being an only child in the family, higher level of maternal and paternal education, and age- and genderadjusted lower BMI and WHtR. An increased frequency of consuming the animal dietary pattern was generally associated with male gender, being an only child in the family, lower level of maternal and paternal education, older age, and age- and gender-adjusted lower BMI and WHtR. Among those who followed a traditional dietary pattern, higher scores were associated with female gender, being an only child in the family, higher family income, higher maternal and paternal education level and younger age.

Table 4 contains data on the prevalence of depression and anxiety disorders and the associated sociodemographic and anthropometric characteristics. The prevalence of depression, anxiety and coexisting depression and anxiety was $11 \cdot 2 \%, 14 \cdot 6 \%$, and $12 \cdot 6 \%$, respectively. A high risk of depression or anxiety was associated with girls, being an only child in the family, low maternal and paternal educational level, low family income and lack of physical activity.

Table 5 shows that the prevalence of mental disorders, especially coexisting depression and anxiety, was associated with higher tertiles of the snack and animal food dietary pattern scores; however, an inverse correlation was observed between the traditional dietary pattern and depression and anxiety.

Results from multiple logistic regression analyses, with all three dietary patterns entered simultaneously as exposure variables, and categorical pure depression, pure anxiety and coexisting depression and anxiety as outcomes, demonstrated that the highest tertile scores in the snack dietary pattern were associated with higher odds for depression and anxiety disorders, associations which were strengthened by all adjustments for age, gender, maternal and paternal education, family income, BMI and physical activity in model 3 (Table 6). The traditional dietary pattern was associated with decreased odds for the three categories of mental disorders in the unadjusted and adjusted analyses. 
Table 2 Factor-loading matrix for the major factors (diet patterns) identified using food consumption data from the $\mathrm{FFQ}^{*}$ : adolescents ( $n$ 5003) aged 11-16 years, Bengbu, China, 2010

\begin{tabular}{|c|c|c|c|}
\hline Food or food group & Snack & Animal food & Traditional \\
\hline Pancake & - & 0.39 & 0.24 \\
\hline Red meat & - & 0.50 & 0.33 \\
\hline Organ meat & - & 0.53 & $0 \cdot 25$ \\
\hline Poultry & - & 0.60 & 0.24 \\
\hline Fish and other fishery products & - & 0.45 & 0.32 \\
\hline Processed meat & - & 0.61 & - \\
\hline Bacon & $0 \cdot 22$ & 0.65 & - \\
\hline Meat balls & $0 \cdot 21$ & 0.55 & - \\
\hline Steamed stuffed-bun & - & 0.51 & - \\
\hline Fried meat & 0.44 & 0.54 & - \\
\hline Fried vegetables & $0 \cdot 40$ & 0.41 & - \\
\hline Roast meat & 0.42 & 0.49 & - \\
\hline Sauerkraut & - & $0 \cdot 32$ & - \\
\hline Fried pasta & $0 \cdot 26$ & 0.43 & - \\
\hline Fast food & 0.45 & 0.42 & - \\
\hline Preserved fruit & 0.55 & - & 0.28 \\
\hline Yoghurt & 0.45 & - & 0.38 \\
\hline Sweet course & 0.54 & $0 \cdot 20$ & $0 \cdot 22$ \\
\hline Frozen confection & 0.56 & $0 \cdot 30$ & - \\
\hline Chocolate & $0 \cdot 60$ & - & - \\
\hline Candy & 0.57 & - & - \\
\hline Nut & 0.49 & - & $0 \cdot 20$ \\
\hline Tea or tea drink & 0.52 & 0.28 & - \\
\hline Carbonated drinks & 0.54 & $0 \cdot 37$ & - \\
\hline Flavoured milk drink & $0 \cdot 60$ & - & - \\
\hline Fruit/vegetable juice & 0.53 & - & 0.27 \\
\hline Staple food (for Chinese) & - & - & 0.42 \\
\hline Gruel & - & - & 0.52 \\
\hline Oatmeal & - & - & $0 \cdot 32$ \\
\hline Whole grains & - & - & 0.47 \\
\hline Egg & - & 0.22 & 0.55 \\
\hline Fresh yellow or red vegetables & - & - & $0 \cdot 66$ \\
\hline Fresh green leafy vegetables & - & - & 0.73 \\
\hline Fresh fruit & $0 \cdot 25$ & - & 0.63 \\
\hline Soya products & - & - & 0.54 \\
\hline Soya milk & $0 \cdot 27$ & - & $0 \cdot 47$ \\
\hline Milk & 0.23 & - & 0.51 \\
\hline
\end{tabular}

*Absolute values $<0.20$ were not listed in the table for simplicity. 'Bread' item was excluded.

\section{Discussion}

In the present cross-sectional study among Chinese students attending junior high school, we have demonstrated a relationship between major dietary patterns and mental disorders. We used factor analysis to identify three major dietary patterns, specifically snack, animal food and traditional dietary patterns, which explained $35 \%$ of the variance. The value was low but similar to the outcomes in previous studies ${ }^{(29,30)}$.

High intakes of snacks and animal foods were shown to be associated with mental disorders, and a high intake of a traditional diet was associated with a decreased likelihood of mental disorders. These findings provide a new viewpoint for a multi-focus intervention aiming to improve mental health in Chinese adolescents.

The results suggest that high consumption of unhealthy diets (animal food and snack patterns), rich in energydense but nutrient-poor foods and snacks, is associated with a higher risk of depression and anxiety. These findings are in agreement with two recent epidemiological studies ${ }^{(31,32)}$. Specifically, a positive correlation was shown between snack food intake and mental disorders among adults and older adolescents. Evidence from an observational study in Asian countries suggests that there is a correlation between sugar consumption and the annual rate of depression ${ }^{(33)}$. In a survey of 2579 Chinese college students, the relationship between food consumption frequency, perceived stress and depression was studied, and a higher intake of snack foods was shown to be significantly associated with depression ${ }^{(32)}$. Overconsumption of snacks may contribute to excessive energy, fat and sugar intakes in adolescents, and snacks provide few of the micronutrients which are essential for optimal neurotransmitter function and involved in the pathologies of various psychiatric disorders, such as depression, anxiety, panic disorder and personality disorders ${ }^{(34,35)}$.

In the current study gender was an important determinant of intake with respect to snack diets. Girls consumed more snack foods than boys. The findings are also supported by previous conclusions that females were ambivalent towards eating snacks, perceiving snacks as unhealthy, but preferred to eat especially under stress $^{(36,37)}$. However, other authors have reported in Australian children and adolescents that boys had more extra food intake compared with girls ${ }^{(38)}$.

The traditional diet pattern, consisting of whole grains, fruits, vegetables, rice and some soya products, was inversely associated with the prevalence of psychological symptoms in our study. The findings herein are supported by findings from the Seguimiento Universidad de Navarra (SUN) prospective cohort study ${ }^{(39)}$. In the SUN study adherence to a Mediterranean diet, ensuring adequate intakes of fruits, nuts, vegetables, cereals, legumes and fish, was considered an important protector against depression in adolescents ${ }^{(39)}$. In addition to the aforementioned whole diet patterns, increased intakes of individual foods, such as vegetables, fruits, dairy and cereals, have also been linked with promoting or maintaining a healthy mental status ${ }^{(40-43)}$. In the 1970 British cohort study ${ }^{(44)}$, children with higher mental abilities reported more frequent intakes of fruits, vegetables, wholegrain bread and low-fat meats, but lower intakes of chips, non-wholegrain bread and snacks as adults. In recent years, Western foods have become more available and popular among children and adolescents relative to traditional diet alternatives ${ }^{(23,45)}$. Therefore, we suggest that further research regarding the impact of a decreased intake of healthy foods on mental disorders is needed.

With respect to the validity of capturing complex behaviours and potentially interactive effects among special nutrients that might impact mental health, there is growing recognition that special dietary patterns and their effects on mental health should be of concern in adolescents. In a recent study in Australia, Robinson et al. ${ }^{(10)}$ examined 
Table 3 Distribution of demographic/anthropometric characteristics according to tertile of dietary pattern scores: adolescents ( $n$ 5003) aged $11-16$ years, Bengbu, China, 2010

\begin{tabular}{|c|c|c|c|c|c|c|c|c|c|c|c|c|c|c|c|c|c|c|c|c|c|}
\hline & \multicolumn{7}{|c|}{ Snack } & \multicolumn{7}{|c|}{ Animal food } & \multicolumn{7}{|c|}{ Traditional } \\
\hline & \multicolumn{2}{|c|}{$\begin{array}{c}\mathrm{T} 1 \\
(n \mathrm{1661})\end{array}$} & \multicolumn{2}{|c|}{$\begin{array}{c}\text { T2 } \\
(n 1648)\end{array}$} & \multicolumn{2}{|c|}{$\begin{array}{c}\text { T3 } \\
(n 1694)\end{array}$} & \multirow[b]{2}{*}{$P^{\star}$} & \multicolumn{2}{|c|}{$\begin{array}{c}\mathrm{T} 1 \\
(n \mathrm{1662})\end{array}$} & \multicolumn{2}{|c|}{$\begin{array}{c}\text { T2 } \\
(n \text { 1647) }\end{array}$} & \multicolumn{2}{|c|}{$\begin{array}{c}\text { T3 } \\
(n 1694)\end{array}$} & \multirow[b]{2}{*}{$P^{\star}$} & \multicolumn{2}{|c|}{$\begin{array}{c}\mathrm{T} 1 \\
(n \mathrm{1653})\end{array}$} & \multicolumn{2}{|c|}{$\begin{array}{c}\text { T2 } \\
(n 1644)\end{array}$} & \multicolumn{2}{|c|}{$\begin{array}{c}\text { T3 } \\
(n \text { 1706) }\end{array}$} & \multirow[b]{2}{*}{$P^{\star}$} \\
\hline & \multicolumn{2}{|c|}{$\%$} & \multicolumn{2}{|c|}{$\%$} & \multicolumn{2}{|c|}{$\%$} & & \multicolumn{2}{|c|}{$\%$} & \multicolumn{2}{|c|}{$\%$} & \multicolumn{2}{|c|}{$\%$} & & \multicolumn{2}{|c|}{$\%$} & \multicolumn{2}{|c|}{$\%$} & \multicolumn{2}{|c|}{$\%$} & \\
\hline \multicolumn{22}{|l|}{ Sext } \\
\hline Male & 38 & $3 \cdot 1$ & 31 & 1.0 & 30 & .9 & $<0.001$ & 24 & & 32 & .5 & 43 & $3 \cdot 3$ & $<0.001$ & 34 & & 32 & & & 2.8 & 0.02 \\
\hline Female & 27 & .9 & 35 & $5 \cdot 0$ & 37 & 7.0 & & 43 & 0 & 33 & $3 \cdot 4$ & 23 & $3 \cdot 6$ & & 31 & & 33 & 4 & & 5.5 & \\
\hline Only childt & & & & & & & & & & & & & & & & & & & & & \\
\hline Yes & 34 & .5 & 32 & $2 \cdot 3$ & 33 & $3 \cdot 1$ & $<0.001$ & 34 & $\cdot 1$ & 31 & 1.9 & 33 & 3.9 & 0.01 & 30 & & 33 & 1 & & $6 \cdot 6$ & $<0.001$ \\
\hline No & 28 & $\cdot 7$ & 35 & 5.0 & 36 & 3 & & 30 & $\cdot 1$ & 36 & 3 & 33 & $3 \cdot 6$ & & 42 & & 31 & .9 & 25 & $5 \cdot 5$ & \\
\hline Family incomet & & & & & & & & & & & & & & & & & & & & & \\
\hline Low & 44 & .9 & 29 & $9 \cdot 3$ & 25 & $5 \cdot 8$ & $<0.001$ & 32 & 0 & 32 & 2.0 & 35 & 5.9 & $0 \cdot 40$ & 35 & & 34 & 0 & & .9 & $<0.001$ \\
\hline Middle & 33 & $\cdot 7$ & 34 & $4 \cdot 3$ & 32 & 2.0 & & 32 & 6 & 33 & $3 \cdot 7$ & 33 & 3.7 & & 35 & & 32 & 6 & & 2.2 & \\
\hline High & 30 & $\cdot 0$ & 30 & 6 & 39 & $9 \cdot 4$ & & 34 & $\cdot 9$ & 31 & $1 \cdot 2$ & 33 & 3.9 & & 27 & & 33 & $\cdot 1$ & 39 & $9 \cdot 0$ & \\
\hline Maternal educationt & & & & & & & & & & & & & & & & & & & & & \\
\hline Primary schooling/illiterate & 36 & 5 & 33 & $3 \cdot 5$ & 30 & 0 & 0.04 & 27 & $\cdot 7$ & 36 & $\cdot 3$ & 36 & $5 \cdot 0$ & $<0.001$ & 46 & & 31 & .4 & & $1 \cdot 9$ & $<0.001$ \\
\hline Secondary schooling & 32 & 3 & 33 & $3 \cdot 4$ & 34 & $1 \cdot 2$ & & 31 & 8 & 33 & $3 \cdot 1$ & 35 & $5 \cdot 1$ & & 34 & & 32 & 5 & & $2 \cdot 9$ & \\
\hline University or more & 34 & $\cdot 6$ & 32 & 2.9 & 32 & 2.6 & & 36 & $\cdot 6$ & 32 & $2 \cdot 2$ & 31 & $1 \cdot 3$ & & 23 & & 34 & .4 & & $2 \cdot 2$ & \\
\hline Unknown & 33 & $3 \cdot 2$ & 32 & 2.9 & 33 & 3.9 & & 36 & $\cdot 4$ & 31 & .0 & 32 & 2.6 & & 44 & & 31 & .0 & & 4.9 & \\
\hline Paternal educationt & & & & & & & & & & & & & & & & & & & & & \\
\hline Primary schooling/illiterate & 32 & 6 & 33 & $3 \cdot 6$ & 33 & 3.9 & 0.05 & 25 & $\cdot 7$ & 35 & 5.9 & 38 & 3.5 & $<0.001$ & 50 & & 29 & $\cdot 3$ & & $0 \cdot 1$ & $<0.001$ \\
\hline Secondary schooling & 31 & .9 & 33 & 3.0 & 35 & $5 \cdot 1$ & & 31 & 0 & 33 & 3.5 & 35 & 5.4 & & 36 & & 33 & 4 & & $0 \cdot 3$ & \\
\hline University or more & 35 & 6 & 33 & 3.0 & 31 & $\cdot 3$ & & 37 & 5 & 31 & .7 & 30 & .8 & & 23 & & 33 & 6 & & $3 \cdot 1$ & \\
\hline Unknown & 29 & $\cdot 9$ & 31 & $1 \cdot 6$ & 38 & $3 \cdot 5$ & & 33 & $\cdot 0$ & 32 & $\cdot 1$ & 34 & 4.9 & & 45 & & 28 & 5 & & $6 \cdot 0$ & \\
\hline & Mean & SE & Mean & SE & Mean & SE & $P$ & Mean & SE & Mean & SE & Mean & SE & $P$ & Mean & SE & Mean & SE & Mean & SE & $P$ \\
\hline Age & $13 \cdot 21$ & & $13 \cdot 14$ & 0.02 & $13 \cdot 20$ & 0.02 & $0 \cdot 11$ & $13 \cdot 11$ & 0.02 & $13 \cdot 21$ & 0.99 & $13 \cdot 26$ & 0.02 & $<0.001$ & $13 \cdot 26$ & 0.02 & $13 \cdot 16$ & 0.02 & $13 \cdot 12$ & 0.02 & $<0.001$ \\
\hline BMl‡ & $20 \cdot 73$ & 0.09 & $20 \cdot 44$ & 0.09 & $20 \cdot 22$ & 0.09 & $<0.001$ & $20 \cdot 73$ & 0.09 & $20 \cdot 48$ & 0.09 & $20 \cdot 19$ & 0.09 & $<0.001$ & $20 \cdot 39$ & 0.09 & $20 \cdot 51$ & 0.09 & $20 \cdot 49$ & 0.09 & 0.61 \\
\hline WHtR $\ddagger$ & 0.44 & 0.002 & 0.43 & 0.002 & 0.43 & 0.002 & $<0.001$ & 0.44 & 0.002 & 0.44 & 0.002 & 0.43 & 0.002 & 0.86 & 0.44 & 0.002 & 0.44 & 0.002 & 0.43 & 0.002 & $0 \cdot 11$ \\
\hline
\end{tabular}

T1, lowest tertile of dietary pattern's score; T2, intermediate tertile of dietary pattern's score; T3, highest tertile of dietary pattern's score; WHtR, waist-to-height ratio.

${ }^{*}$ ANOVA was used for continuous variables and the $\chi^{2}$ test for categorical variables to calculate $P$ for trend across categories of dietary pattern.

$\ddagger P$ value adjusted for age and gender. 
Table 4 Association between demographic/anthropometric characteristics and pure depression, pure anxiety and coexisting depression and anxiety: adolescents ( $n$ 5003) aged 11-16 years, Bengbu, China, 2010

\begin{tabular}{|c|c|c|c|c|c|c|c|c|c|}
\hline & \multicolumn{3}{|c|}{$\begin{array}{l}\text { Pure depression* } \\
(\text { ( } 560,11 \cdot 2 \%)\end{array}$} & \multicolumn{3}{|c|}{$\begin{array}{l}\text { Pure anxiety } \dagger \\
(n 732,14 \cdot 6 \%)\end{array}$} & \multicolumn{3}{|c|}{$\begin{array}{l}\text { Coexisting depression } \\
\text { and anxiety } \\
(n 629,12 \cdot 6 \%)\end{array}$} \\
\hline & OR & $95 \% \mathrm{Cl}$ & $P$ & OR & $95 \% \mathrm{Cl}$ & $P$ & OR & $95 \% \mathrm{Cl}$ & $P$ \\
\hline \multicolumn{10}{|l|}{ Gender } \\
\hline Female & $1 \cdot 40$ & $1 \cdot 15,1 \cdot 71$ & $<0.001$ & $1 \cdot 04$ & $0 \cdot 87,1 \cdot 26$ & 0.65 & $1 \cdot 47$ & $1 \cdot 22,1 \cdot 78$ & $<0.001$ \\
\hline Male & $1 \cdot 00$ & & & $1 \cdot 00$ & & & 1.00 & & \\
\hline \multicolumn{10}{|l|}{ Age (years) $\ddagger$} \\
\hline $15 \sim$ & $1 \cdot 24$ & $0.89,1 \cdot 74$ & $0 \cdot 21$ & 0.91 & $0.66,1 \cdot 24$ & 0.54 & $2 \cdot 10$ & $1 \cdot 53,2 \cdot 88$ & $<0.001$ \\
\hline $13-14$ & $1 \cdot 16$ & $0 \cdot 94,1 \cdot 42$ & $0 \cdot 17$ & 1.04 & $0 \cdot 87,1 \cdot 25$ & 0.64 & $1 \cdot 73$ & $1 \cdot 40,2 \cdot 14$ & $<0.001$ \\
\hline 12 & $1 \cdot 00$ & & & $1 \cdot 00$ & & & $1 \cdot 00$ & & \\
\hline \multicolumn{10}{|l|}{ Maternal education $\ddagger$} \\
\hline Unknown & 0.93 & $0 \cdot 63,1 \cdot 36$ & $0 \cdot 70$ & 0.78 & $0 \cdot 52,1 \cdot 16$ & 0.22 & 0.88 & $0 \cdot 61,1 \cdot 27$ & 0.50 \\
\hline University or more & 0.57 & $0.42,0.78$ & $<0.001$ & 0.85 & $0.63,1 \cdot 15$ & $0 \cdot 30$ & 0.49 & $0.36,0.67$ & $<0.001$ \\
\hline Secondary schooling & 0.67 & $0.51,0.90$ & 0.01 & $1 \cdot 00$ & $0.75,1.32$ & 0.98 & $0 \cdot 70$ & $0.54,0.92$ & 0.01 \\
\hline Primary schooling/illiterate & 1.00 & & & 1.00 & & & 1.00 & & \\
\hline \multicolumn{10}{|l|}{ Paternal education $\ddagger$} \\
\hline Unknown & 0.64 & $0.42,0.95$ & 0.03 & 0.81 & $0.52,1.25$ & 0.33 & $0 \cdot 74$ & $0 \cdot 49,1 \cdot 11$ & $0 \cdot 15$ \\
\hline University or more & 0.42 & $0.31,0.58$ & $<0.001$ & $0 \cdot 86$ & $0.62,1 \cdot 21$ & 0.39 & 0.49 & $0.35,0.67$ & $<0.001$ \\
\hline Secondary schooling & 0.45 & $0.33,0.61$ & $<0.001$ & 0.96 & $0.69,1.33$ & $0 \cdot 80$ & $0 \cdot 70$ & $0.51,0.95$ & 0.02 \\
\hline Primary schooling/illiterate & $1 \cdot 00$ & & & $1 \cdot 00$ & & & $1 \cdot 00$ & & \\
\hline \multicolumn{10}{|l|}{ Family income } \\
\hline Low & $1 \cdot 67$ & $1 \cdot 18,2 \cdot 36$ & $<0.001$ & 0.97 & $0 \cdot 68,1 \cdot 40$ & $0 \cdot 89$ & $1 \cdot 90$ & $1 \cdot 39,2 \cdot 59$ & $<0.001$ \\
\hline Middle & 1.00 & & & 1.00 & & & $1 \cdot 00$ & & \\
\hline High & 1.04 & $0 \cdot 85,1 \cdot 26$ & $0 \cdot 71$ & 0.96 & $0 \cdot 81,1 \cdot 15$ & 0.68 & $0 \cdot 71$ & $0.58,0.86$ & $<0.001$ \\
\hline \multicolumn{10}{|l|}{ Physical activity (d/week)‡ } \\
\hline 0 & 1.00 & & & 1.00 & & & 1.00 & & \\
\hline 1 & 0.78 & $0.62,0.98$ & 0.03 & 0.96 & $0 \cdot 77,1 \cdot 20$ & 0.74 & 0.75 & $0.60,0.94$ & 0.01 \\
\hline 2 & $0 \cdot 66$ & $0.51,0.84$ & $<0.001$ & $1 \cdot 21$ & $0.97,1.51$ & $0 \cdot 10$ & 0.64 & $0.50,0.81$ & $<0.001$ \\
\hline 3 or more & 0.50 & $0.39,0.65$ & $<0.001$ & 0.87 & $0.69,1.09$ & 0.21 & 0.55 & $0 \cdot 44,0 \cdot 70$ & $<0.001$ \\
\hline \multicolumn{10}{|l|}{ BMl $\left(\mathrm{kg} / \mathrm{m}^{2}\right)$} \\
\hline$<18 \cdot 5$ & $1 \cdot 02$ & $0 \cdot 84,1 \cdot 24$ & 0.85 & 0.92 & $0.77,1.09$ & 0.34 & 0.82 & $0.68,0.99$ & 0.04 \\
\hline $18 \cdot 5-23 \cdot 9$ & $1 \cdot 00$ & & & $1 \cdot 00$ & & & $1 \cdot 00$ & & \\
\hline $24 \cdot 0-27 \cdot 9$ & $1 \cdot 19$ & $0.91,1.57$ & 0.21 & 0.89 & $0 \cdot 69,1 \cdot 16$ & $0 \cdot 40$ & 0.79 & $0 \cdot 60,1 \cdot 05$ & $0 \cdot 11$ \\
\hline$\geq 28 \cdot 0$ & $0 \cdot 78$ & $0 \cdot 49,1 \cdot 25$ & 0.31 & 0.81 & $0 \cdot 54,1 \cdot 21$ & 0.31 & 0.89 & $0 \cdot 59,1 \cdot 34$ & 0.58 \\
\hline \multicolumn{10}{|l|}{ WHtR } \\
\hline$<0.5$ & $1 \cdot 00$ & & & $1 \cdot 00$ & & & $1 \cdot 00$ & & \\
\hline \multirow{2}{*}{\multicolumn{10}{|c|}{ Weight stature }} \\
\hline & & & & & & & & & \\
\hline Normal & $1 \cdot 00$ & & & $1 \cdot 00$ & & & $1 \cdot 00$ & & \\
\hline Lean & 1.00 & $0 \cdot 81,1 \cdot 23$ & 1.00 & 1.03 & $0 \cdot 85,1 \cdot 24$ & $0 \cdot 76$ & 1.07 & $0 \cdot 87,1 \cdot 31$ & 0.54 \\
\hline Overweight/obese & 0.95 & $0 \cdot 77,1 \cdot 19$ & 0.67 & $1 \cdot 13$ & $0.93,1.37$ & 0.22 & $1 \cdot 35$ & $1 \cdot 11,1.65$ & $<0.001$ \\
\hline
\end{tabular}

WHtR, waist-to-height ratio.

${ }^{*}$ Depression self-rating scale score $\geq 15$.

+ Child anxiety related emotional disorders scale score $\geq 23$.

$\ddagger$ Self-reported variables.

lifestyle and demographic factors to identify the associations with mental problems (withdrawal, anxiety and depression, somatic complaints, delinquency, aggression) among younger adolescents. Six food groups were derived from a 212-item FFQ. The authors concluded that a higher intake of a 'meat food' diet pattern and an 'extra food' diet pattern (such as takeaway and snack foods) were significantly associated with a higher score on the Child Behaviour Checklist for Ages 4-18.

Although many studies have indicated a relationship between diet and mental disorders, the mechanisms are still not well understood. Some researchers have attempted to explain how diet and nutrition modulate biological processes underpinning mental disorders ${ }^{(46,47)}$; individual nutrients are often highlighted. Nutrients such as vitamin $\mathrm{C}$, vitamin $\mathrm{B}_{12}$, folate, $n$-3 fatty acids and $\alpha$-linolenic acid, flavonoids and $\mathrm{Zn}$ have been verified to maintain psychological well-being. A recent finding also suggested that trans-unsaturated fatty acids have a dose-response effect on clinical depression ${ }^{(48)}$. Therefore, the intake of special nutrients is often considered a mediator of the association between whole diet and mental problems ${ }^{(49-52)}$.

In the current study the prevalence of depression, anxiety and coexisting depression and anxiety was $11 \cdot 2 \%$, $14 \cdot 6 \%$, and $12 \cdot 6 \%$, respectively. The rates of depression, anxiety and coexisting depression and anxiety are in agreement with previous studies regarding psychological symptoms. For example, by using the self-rating scale of the DSM-IV (Diagnostic and Statistical Manual of Mental Disorders, 4th edition) for major depression symptoms, the prevalence of depression was $18.9 \%$ and $17 \cdot 0 \%$, 
Table 5 Prevalence of mental symptoms by tertile of dietary pattern scores: adolescents ( $n$ 5003) aged 11-16 years, Bengbu, China, 2010

\begin{tabular}{|c|c|c|c|c|c|c|c|c|c|c|c|}
\hline \multirow[b]{2}{*}{ Dietary pattern } & \multirow[b]{2}{*}{$n$} & \multicolumn{2}{|c|}{$\begin{array}{l}\text { Without depression } \\
\text { and anxiety }\end{array}$} & \multicolumn{2}{|c|}{ Pure depression } & \multicolumn{2}{|c|}{ Pure anxiety } & \multicolumn{2}{|c|}{$\begin{array}{l}\text { Coexisting depression } \\
\text { and anxiety }\end{array}$} & \multirow[b]{2}{*}{$\chi^{2}$} & \multirow[b]{2}{*}{$P$} \\
\hline & & $n$ & $\%$ & $n$ & $\%$ & $n$ & $\%$ & $n$ & $\%$ & & \\
\hline \multicolumn{12}{|l|}{ Snack } \\
\hline $\mathrm{T} 1$ & 1661 & 1115 & $67 \cdot 1$ & 177 & $10 \cdot 7$ & 195 & $11 \cdot 7$ & 174 & $10 \cdot 5$ & \multirow{3}{*}{$63 \cdot 21$} & \multirow[t]{3}{*}{$<0.001$} \\
\hline T2 & 1648 & 1039 & $63 \cdot 0$ & 160 & $9 \cdot 7$ & 254 & $15 \cdot 4$ & 195 & $11 \cdot 8$ & & \\
\hline T3 & 1694 & 928 & $54 \cdot 8$ & 223 & $13 \cdot 2$ & 283 & $16 \cdot 7$ & 260 & $15 \cdot 3$ & & \\
\hline \multicolumn{12}{|l|}{ Animal food } \\
\hline T1 & 1662 & 1065 & $64 \cdot 1$ & 183 & $11 \cdot 0$ & 215 & $12 \cdot 9$ & 199 & $12 \cdot 0$ & \multirow[t]{3}{*}{$19 \cdot 93$} & \multirow[t]{3}{*}{0.003} \\
\hline T2 & 1647 & 1033 & $62 \cdot 7$ & 191 & $11 \cdot 6$ & 234 & $14 \cdot 2$ & 189 & 11.5 & & \\
\hline T3 & 1694 & 984 & $58 \cdot 1$ & 186 & $11 \cdot 0$ & 283 & $16 \cdot \overline{7}$ & 241 & $14 \cdot 2$ & & \\
\hline \multicolumn{12}{|l|}{ Traditional } \\
\hline T1 & 1653 & 890 & $53 \cdot 8$ & 266 & $16 \cdot 1$ & 232 & $14 \cdot 0$ & 265 & $16 \cdot 0$ & \multirow[t]{3}{*}{$122 \cdot 28$} & \multirow[t]{3}{*}{$<0.001$} \\
\hline T2 & 1644 & 1021 & $62 \cdot 1$ & 172 & $7 \cdot 2$ & 245 & $14 \cdot 9$ & 206 & 12.5 & & \\
\hline T3 & 1706 & 1171 & $68 \cdot 6$ & 122 & $7 \cdot \overline{2}$ & 255 & 14.9 & 158 & $9 \cdot 3$ & & \\
\hline
\end{tabular}

$\mathrm{T} 1$, lowest tertile of dietary pattern's score; T2, intermediate tertile of dietary pattern's score; T3, highest tertile of dietary pattern's score.

Table 6 Odds ratios (95\% confidence intervals) from multiple logistic regression models for pure depression, pure anxiety and coexisting depression and anxiety according to tertile of dietary pattern scores adolescents $(n 5003)$ aged $11-16$ years, Bengbu, China, 2010

\begin{tabular}{|c|c|c|c|c|c|c|c|c|c|}
\hline & \multicolumn{3}{|c|}{ Pure depression } & \multicolumn{3}{|c|}{ Pure anxiety } & \multicolumn{3}{|c|}{ Coexisting depression and anxiety } \\
\hline & $\mathrm{OR}^{*}$ & $95 \% \mathrm{Cl}$ & $P$ & $\mathrm{OR}^{*}$ & $95 \% \mathrm{Cl}$ & $P$ & $\mathrm{OR}^{*}$ & $95 \% \mathrm{Cl}$ & $P$ \\
\hline \multicolumn{10}{|c|}{ Model 1† } \\
\hline \multicolumn{10}{|c|}{ Snack } \\
\hline T2 & 0.92 & $0 \cdot 73,1 \cdot 67$ & 0.49 & $1 \cdot 50$ & $1 \cdot 22,1 \cdot 85$ & $<0.001$ & $1 \cdot 21$ & $0 \cdot 96,1 \cdot 52$ & $0 \cdot 10$ \\
\hline T3 & $1 \cdot 53$ & $1 \cdot 23,1 \cdot 91$ & $<0.001$ & $1 \cdot 85$ & $1 \cdot 50,2 \cdot 27$ & $<0.001$ & $1 \cdot 84$ & $1 \cdot 48,2 \cdot 28$ & $<0.001$ \\
\hline \multicolumn{10}{|c|}{ Animal food } \\
\hline T2 & $1 \cdot 06$ & $0.84,1 \cdot 33$ & 0.64 & $1 \cdot 23$ & $1 \cdot 00,1 \cdot 51$ & 0.05 & 1.02 & $0 \cdot 82,1 \cdot 27$ & 0.88 \\
\hline T3 & 1.09 & $0.87,1.37$ & 0.45 & 1.56 & $1.27,1.91$ & $<0.001$ & $1 \cdot 37$ & $1 \cdot 11,1 \cdot 70$ & $<0.001$ \\
\hline \multicolumn{10}{|c|}{ Traditional } \\
\hline T2 & 0.57 & $0 \cdot 46,0 \cdot 71$ & $<0.001$ & 0.96 & $0 \cdot 78,1 \cdot 17$ & 0.68 & $0 \cdot 70$ & $0.57,0.86$ & $<0.001$ \\
\hline T3 & $0 \cdot 34$ & $0.27,0.43$ & $<0.001$ & $0 \cdot 84$ & $0.69,1.03$ & 0.09 & $0 \cdot 44$ & $0.36,0.55$ & $<0.001$ \\
\hline \multicolumn{10}{|c|}{ Model 2‡ } \\
\hline \multicolumn{10}{|c|}{ Snack } \\
\hline $\mathrm{T} 2$ & 0.93 & $0 \cdot 73,1 \cdot 19$ & 0.58 & $1 \cdot 49$ & $1 \cdot 20,1 \cdot 85$ & $<0.001$ & $1 \cdot 24$ & $0.98,1.56$ & 0.08 \\
\hline T3 & $1 \cdot 56$ & $1 \cdot 24,1 \cdot 96$ & $<0.001$ & $1 \cdot 83$ & $1 \cdot 48,2 \cdot 26$ & $<0.001$ & $1 \cdot 86$ & $1 \cdot 48,2 \cdot 34$ & $<0.001$ \\
\hline \multicolumn{10}{|c|}{ Animal food } \\
\hline T2 & 1.09 & $0 \cdot 87,1 \cdot 38$ & 0.46 & $1 \cdot 35$ & $1 \cdot 09,1 \cdot 67$ & 0.01 & $1 \cdot 10$ & $0 \cdot 88,1 \cdot 40$ & 0.38 \\
\hline T3 & $1 \cdot 20$ & $0.95,1.53$ & $0 \cdot 13$ & $1 \cdot 88$ & $1 \cdot 52,2 \cdot 33$ & $<0.001$ & $1 \cdot 71$ & $1 \cdot 36,2 \cdot 15$ & $<0.001$ \\
\hline \multicolumn{10}{|c|}{ Traditional } \\
\hline T2 & 0.58 & $0.46,0.72$ & $<0.001$ & 0.97 & $0 \cdot 78,1 \cdot 19$ & $0 \cdot 75$ & $0 \cdot 72$ & $0.58,0.89$ & $<0.001$ \\
\hline T3 & 0.35 & $0.28,0.45$ & $<0.001$ & $0 \cdot 85$ & $0.69,1.05$ & $0 \cdot 13$ & 0.47 & $0.37,0.59$ & $<0.001$ \\
\hline \multicolumn{10}{|c|}{ Model $3 \S$} \\
\hline \multicolumn{10}{|c|}{ Snack } \\
\hline T2 & 0.98 & $0 \cdot 77,1 \cdot 25$ & $0 \cdot 86$ & $1 \cdot 38$ & $1 \cdot 08,1 \cdot 65$ & 0.01 & $1 \cdot 27$ & $1 \cdot 00,1 \cdot 61$ & 0.05 \\
\hline T3 & $1 \cdot 64$ & $1 \cdot 30,2 \cdot 06$ & $<0.001$ & $1 \cdot 87$ & $1 \cdot 51,2 \cdot 31$ & $<0.001$ & 1.93 & $1 \cdot 54,2 \cdot 43$ & $<0.001$ \\
\hline \multicolumn{10}{|c|}{ Animal food } \\
\hline T2 & $1 \cdot 08$ & $0 \cdot 86,1 \cdot 37$ & 0.46 & $1 \cdot 34$ & $1 \cdot 08,1 \cdot 65$ & 0.01 & $1 \cdot 10$ & $0 \cdot 88,1 \cdot 39$ & 0.41 \\
\hline T3 & $1 \cdot 21$ & $0.95,1.53$ & 0.13 & $1 \cdot 87$ & $1 \cdot 51,2 \cdot 32$ & $<0.001$ & $1 \cdot 71$ & $1 \cdot 37,2 \cdot 15$ & $<0.001$ \\
\hline \multicolumn{10}{|c|}{ Traditional } \\
\hline T2 & $0 \cdot 61$ & $0.49,0.76$ & $<0.001$ & 0.98 & $0 \cdot 79,1 \cdot 23$ & $0 \cdot 82$ & 0.74 & $0.60,0.92$ & 0.01 \\
\hline T3 & 0.38 & $0.30,0.49$ & $<0.001$ & 0.85 & $0.69,1.04$ & $0 \cdot 12$ & 0.50 & $0.39,0.63$ & $<0.001$ \\
\hline
\end{tabular}

T1, lowest tertile of dietary pattern's score; T2, intermediate tertile of dietary pattern's score; T3, highest tertile of dietary pattern's score.

${ }^{*} \mathrm{~T} 1$ as reference group in all models.

tModel 1: unadjusted.

‡Model 2: adjusted for age, gender, maternal education, paternal education, family income and BMI.

\$Model 3: adjusted per model 2 plus physical activity.

respectively, among 15- and 17-year-old adolescents in Sweden ${ }^{(53)}$. In the present study we screened mental symptoms by using psychological scales rather than clinical diagnostic criteria. Thus, the observed prevalence of mental symptoms was indeed higher than that of major depression and anxiety ${ }^{(54)}$. As a result, the interpretation of the results should be made with caution. In recent decades, Chinese society has experienced a massive socio-economic change and culture shock. Added to intense competition in education, psychological and 
behavioural problems are gradually increasing in the adolescent population. The high prevalence of depression and anxiety in the present findings also reveals that promoting adolescent mental health is needed in China.

There were several limitations in our study. The study had a cross-sectional design, which limited the conclusions to aetiological inferences that unhealthy dietary patterns may lead to mental conditions. Unhealthy food choices may be compensatory mechanisms for mental disorders, rather than a causative factor. It has been shown that depressed individuals report greater preferences for carbohydrates (especially high-carbohydrate foods), increased serotonin release and relief of stress ${ }^{(55)}$, compared with individuals without depression. Therefore, in a further study, a longitudinal design would preclude reverse causality existing in the findings. Except for morphological indices, all other information was selfreported by adolescents and subject to social desirability bias. The rate of unhealthy diets or other risk behaviours may be underestimated. The study used psychological screening scales rather than clinical diagnostic criteria to evaluate depressive symptoms and anxiety, which might lead to an overestimate of the incidence of depression or anxiety in adolescents. The adolescents who participated in the study were mainly from urban areas with Han nationality and lived in the same city, thus affecting the sample representation and further generalization of the results. There are various kinds of foods in the Chinese diet such that it is difficult for younger adolescents to recall portion size of foods they have eaten several days before. The FFQ was designed so that interviewees could provide answers more easily, without information on the portion size of each food item. As a result, the FFQ is limited with respect to the variability of the food consumption. It is impossible to rule out residual confounding or information bias by family variables as a factor in these findings.

\section{Conclusions}

Our study was designed to determine the association between overall diet and depression and anxiety symptoms in a large sample of Chinese adolescents. It was found that the snack and animal food patterns were associated with a high risk of depression and anxiety, while the traditional diet pattern was associated with a low risk for them after adjustment for relevant confounders. The study provided epidemiological evidence of a robust association of traditional, snack and animal food diets with mental symptoms in Chinese urban adolescents. Additional cohort studies involving dietary patterns and mental disorders in Chinese children and adolescents are warranted to investigate the predictive effect of habitual dietary behaviours on mental health in adolescence, as well as adulthood.

\section{Acknowledgements}

This work was supported by the National Natural Science Foundation of China (grant numbers 30972494, 81072310, 30901202 and 30901203). The authors declare that they have no conflict of interest. The authors' contributions were as follows. Conception and design: F.-B.T., J.-H.H., T.-T.W. and H.C.; acquisition of data: T.-T.W., H.C., J.-L.F., L.H., Q.-W.Q. and Y.S.; drafting of the manuscript: T.-T.W.; final approval of the manuscript: T.-T.W., F.-B.T. and J.-H.H.; statistical expertise: T.-T.W., J.-H.H. and F.-B.T. All authors contributed to the interpretation of the data.

\section{References}

1. Kessler RC, Berglund P, Demler O et al. (2005) Lifetime prevalence and age-of-onset distributions of DSM-IV disorders in the National Comorbidity Survey Replication. Arch Gen Psychiatry 62, 593-602.

2. Patel V, Flisher AJ, Hetrick S et al. (2007) Mental health of young people: a global public-health challenge. Lancet 369, 1302-1313.

3. Mufson L, Weissman M, Moreau D et al. (1999) Efficacy of interpersonal psychotherapy for depressed adolescents. Arch Gen Psychiatry 56, 573-579.

4. Lewinsohn PM, Hops H, Roberts RE et al. (1993) Adolescent psychopathology: I. Prevalence and incidence of depression and other DSM-III-R disorders in high school students. J Abnorm Psychol 102, 133-144.

5. Clark D \& Kirisci L (1996) Posttraumatic stress disorder, depression, alcohol use disorders and quality of life in adolescents. Anxiety 2, 226-233.

6. Goodman E \& Whitaker RC (2002) A prospective study of the role of depression in the development and persistence of adolescent obesity. Pediatrics 110, 497-504.

7. Kessler RC, DuPont RL, Berglund P et al. (1999) Impairment in pure and comorbid generalized anxiety disorder and major depression at 12 months in two national surveys. Am J Psychiatry 156, 1915-1923.

8. Brady EU \& Kendall PC (1992) Comorbidity of anxiety and depression in children and adolescents. Psychol Bull 111, 244-255.

9. Hu F, Manson J, Stampfer M et al. (2001) Diet, lifestyle, and the risk of type 2 diabetes mellitus in women. $N$ Engl J Med 345, 790-797.

10. Robinson M, Kendall GE, Jacoby P et al. (2011) Lifestyle and demographic correlates of poor mental health in early adolescence. J Paediatr Child Health 47, 54-61.

11. Navarro J, Goutet JM, Roy C et al. (1980) Folic acid deficiency and depression of cellular immunity. Arch Fr Pediatr 37, 279.

12. Molteni R, Barnard RJ, Ying Z et al. (2002) A high-fat, refined sugar diet reduces hippocampal brain-derived neurotrophic factor, neuronal plasticity, and learning. Neuroscience 112, 803-814.

13. Jacka FN, Kremer PR, Leslie ER et al. (2010) Associations between diet quality and depressed mood in adolescents: results from the Australian Healthy Neighbourhoods Study. Aust N Z J Psychiatry 44, 435-442.

14. Jacka FN, Pasco JA, Mykletun A et al. (2010) Association of Western and traditional diets with depression and anxiety in women. Am J Psychiatry 167, 305-311.

15. Howard AL, Robinson M, Smith GJ et al. (2011) ADHD is associated with a 'Western' dietary pattern in adolescents. J Atten Disord 15, 403-411. 
16. Li Y, Zhang J \& McKeown RE (2009) Cross-sectional assessment of diet quality in individuals with a lifetime history of attempted suicide. Psychiatry Res 165, 111-119.

17. O'Sullivan TA, Robinson M, Kendall GE et al. (2009) A good-quality breakfast is associated with better mental health in adolescence. Public Health Nutr 12, 249-258.

18. Slater B, Enes CC, Lopez RV et al. (2010) Validation of a food frequency questionnaire to assess the consumption of carotenoids, fruits and vegetables among adolescents: the method of triads. Cad Saude Publica 26, 2090-2100.

19. Jones-McLean E, Shatenstein B \& Whiting S (2010) Dietary patterns research and its applications to nutrition policy for the prevention of chronic disease among diverse North American populations. Appl Physiol Nutr Metab 35, 195-198.

20. Oddy WH, Robinson M, Ambrosini GL et al. (2009) The association between dietary patterns and mental health in early adolescence. Prev Med 49, 39-44.

21. Wang Z, Zhai F, Du S et al. (2008) Dynamic shifts in Chinese eating behaviors. Asia Pac J Clin Nutr 17, 123-130.

22. Wang Y, Popkin B \& Zhai F (1998) The nutritional status and dietary pattern of Chinese adolescents, 1991 and 1993. Eur J Clin Nutr 52, 908-916.

23. Birleson P (1981) The validity of depressive disorder in childhood and the development of a self-rating scale: a research report. J Child Psychol Psychiatry 22, 73-88.

24. Linyan S, Kai W \& Yan Z (2003) Norm of the depression self-rating scale for children in Chinese urban children. Chin Mental Health J 8, 547-549.

25. Birmaher B, Khetarpal S, Brent D et al. (1997) The screen for child anxiety related emotional disorders (SCARED): scale construction and psychometric characteristics. J Am Acad Child Adolesc Psychiatry 36, 545-553.

26. Birmaher B, Brent D, Chiappetta L et al. (1999) Psychometric properties of the Screen for Child Anxiety Related Emotional Disorders (SCARED): a replication study. $J \mathrm{Am}$ Acad Child Adolesc Psychiatry 38, 1230-1236.

27. Su L, Wang K, Fan F et al. (2008) Reliability and validity of the screen for child anxiety related emotional disorders (SCARED) in Chinese children. I Anxiety Disord 22, 612-621.

28. Prochaska J, Sallis J \& Long B (2001) A physical activity screening measure for use with adolescents in primary care. Arch Pediatr Adolesc Med 155, 554-559.

29. Hu FB, Rimm E, Smith-Warner SA et al. (1999) Reproducibility and validity of dietary patterns assessed with a foodfrequency questionnaire. Am J Clin Nutr 69, 243-249.

30. Newby P \& Tucker KL (2004) Empirically derived eating patterns using factor or cluster analysis: a review. Nutr Rev 62, 177-203.

31. Crawford GB, Khedkar A, Flaws JA et al. (2011) Depressive symptoms and self-reported fast-food intake in midlife women. Prev Med 52, 254-257.

32. Liu C, Xie B, Chou CP et al. (2007) Perceived stress, depression and food consumption frequency in the college students of China Seven Cities. Physiol Behav 92, 748-754.

33. Westover AN \& Marangell LB (2002) A cross-national relationship between sugar consumption and major depression? Depress Anxiety 16, 118-120.

34. Stein DJ \& Stahl S (2000) Serotonin and anxiety: current models. Int Clin Psychopharmacol 15, Suppl. 2, S1-S6.

35. Wallin MS \& Rissanen A (1994) Food and mood: relationship between food, serotonin and affective disorders. Acta Psychiatr Scand 89, 36-40.
36. Grogan SC, Bell R \& Conner M (1997) Eating sweet snacks: gender differences in attitudes and behaviour. Appetite 28, 19-31.

37. Zellner DA, Loaiza S, Gonzalez Z et al. (2006) Food selection changes under stress. Physiol Behav 87, 789-793.

38. Rangan AM, Randall D, Hector DJ et al. (2008) Consumption of 'extra' foods by Australian children: types, quantities and contribution to energy and nutrient intakes. Eur J Clin Nutr 62, 356-364.

39. Sanchez-Villegas A, Henriquez P, Bes-Rastrollo $\mathrm{M}$ et al. (2006) Mediterranean diet and depression. Public Health Nutr 9, 1104-1109.

40. Nemets H, Nemets B, Apter A et al. (2006) Omega-3 treatment of childhood depression: a controlled, doubleblind pilot study. Am J Psychiatry 163, 1098-1100.

41. Ramakrishnan U, Imhoff-Kunsch B \& DiGirolamo AM (2009) Role of docosahexaenoic acid in maternal and child mental health. Am J Clin Nutr 89, issue 3, 958S-962S.

42. Pfeiffer SI, Norton J, Nelson L et al. (1995) Efficacy of vitamin $\mathrm{B}_{6}$ and magnesium in the treatment of autism: a methodology review and summary of outcomes. J Autism Dev Disord 25, 481-493.

43. Kaplan BJ, Fisher JE, Crawford SG et al. (2004) Improved mood and behavior during treatment with a mineralvitamin supplement: an open-label case series of children. J Child Adolesc Psychopharmacol 14, 115-122.

44. Batty GD, Deary IJ, Schoon I et al. (2007) Childhood mental ability in relation to food intake and physical activity in adulthood: the 1970 British Cohort Study. Pediatrics 119, e38-e45.

45. Adair LS \& Popkin BM (2005) Are child eating patterns being transformed globally? Obes Res 13, 1281-1299.

46. Bourre JM (2006) Effects of nutrients (in food) on the structure and function of the nervous system: update on dietary requirements for brain. Part 1: micronutrients. J Nutr Health Aging 10, 377-385.

47. Engelhart MJ, Geerlings MI, Ruitenberg A et al. (2002) Dietary intake of antioxidants and risk of Alzheimer disease. JAMA 287, 3223-3229.

48. Sánchez-Villegas A, Verberne L, De Irala J et al. (2011) Dietary fat intake and the risk of depression: the SUN Project. PLoS One 6, e16268.

49. Bjelland I, Tell GS, Vollset SE et al. (2003) Folate, vitamin $\mathrm{B}_{12}$, homocysteine, and the MTHFR $677 \mathrm{C} \rightarrow$ T polymorphism in anxiety and depression: the Hordaland Homocysteine Study. Arch Gen Psychiatry 60, 618-626.

50. Alpert JE \& Fava M (1997) Nutrition and depression: the role of folate. Nutr Rev 55, 145-149.

51. Parker G, Gibson NA, Brotchie H et al. (2006) Omega-3 fatty acids and mood disorders. Am J Psychiatry 163, 969-978.

52. Ng F, Berk M, Dean O et al. (2008) Oxidative stress in psychiatric disorders: evidence base and therapeutic implications. Int J Neuropsychopharmacol 11, 851-876.

53. Sjoberg RL, Nilsson KW \& Leppert J (2005) Obesity, shame, and depression in school-aged children: a populationbased study. Pediatrics 116, e389-e392.

54. Roberts RE, Roberts CR \& Chen YR (1997) Ethnocultural differences in prevalence of adolescent depression. Am J Community Psychol 25, 95-110.

55. Wurtman RJ \& Wurtman JJ (1995) Brain serotonin, carbohydrate-craving, obesity and depression. Obes Res 3, Suppl. 4, 477S-480S. 